\title{
Pathogenic Leptospires Modulate Protein Expression and Post-translational Modifications in Response to Mammalian Host Signals
}

\begin{abstract}
Jarlath E. Nally ${ }^{1 *}$, Andre A. Grassmann ${ }^{2,3}$, Sébastien Planchon ${ }^{4}$, Kjell Sergeant ${ }^{4}$, Jenny Renaut ${ }^{4}$, Janakiram Seshu ${ }^{5}$, Alan J. McBride ${ }^{2,6}$ and Melissa J. Caimano ${ }^{3}$

${ }^{1}$ Infectious Bacterial Diseases Research, National Animal Disease Center, United States Department of Agriculture, Agricultural Research Service, Ames, IA, United States, ${ }^{2}$ Biotechnology Unit, Technological Development Center, Federal University of Pelotas, Pelotas, Brazil, ${ }^{3}$ Departments of Medicine, Pediatrics, and Molecular Biology and Biophysics, University of Connecticut Health Center, Farmington, CT, United States, ${ }^{4}$ Environmental Research and Innovation Department, Luxembourg Institute of Science and Technology, Belvaux, Luxembourg, ${ }^{5}$ Department of Biology, University of Texas San Antonia, San Antonia, TX, United States, ${ }^{6}$ Gonçalo Moniz Institute, Oswaldo Cruz Foundation, Ministry of Health, Salvador, Brazil
\end{abstract}

Pathogenic species of Leptospira cause leptospirosis, a bacterial zoonotic disease with a global distribution affecting over one million people annually. Reservoir hosts of leptospirosis, including rodents, dogs, and cattle, exhibit little to no signs of disease but shed large numbers of organisms in their urine. Transmission occurs when mucosal surfaces or abraded skin come into contact with infected urine or urine-contaminated water or soil. Whilst little is known about how Leptospira adapt to and persist within a reservoir host, in vitro studies suggest that leptospires alter their transcriptomic and proteomic profiles in response to environmental signals encountered during mammalian infection. We applied the dialysis membrane chamber (DMC) peritoneal implant model to compare the whole cell proteome of in vivo derived leptospires with that of leptospires cultivated in vitro at $30^{\circ} \mathrm{C}$ and $37^{\circ} \mathrm{C}$ by 2 -dimensional difference in-gel electrophoresis (2-D DIGE). Of 1,735 protein spots aligned across 9 2-D DIGE gels, 202 protein spots were differentially expressed $(p<0.05$, fold change $>1.25$ or $<-1.25$ ) across all three conditions. Differentially expressed proteins were excised for identification by mass spectrometry. Data are available via ProteomeXchange with identifier PXD006995. The greatest differences were detected when DMC-cultivated leptospires were compared with IV30- or IV37-cultivated leptospires, including the increased expression of multiple isoforms of Loa22, a known virulence factor. Unexpectedly, 20 protein isoforms of LipL32 and 7 isoforms of LipL41 were uniformly identified by DIGE as differentially expressed, suggesting that unique post-translational modifications (PTMs) are operative in response to mammalian host conditions. To test this hypothesis, a rat model of persistent renal colonization was used to isolate leptospires directly from the urine of experimentally infected rats. Comparison of urinary derived leptospires to IV30 leptospires by 2-D immunoblotting confirmed that modification of proteins with trimethyllysine and acetyllysine occurs to a different degree in response to mammalian host signals 
encountered during persistent renal colonization. These results provide novel insights into differential protein and PTMs present in response to mammalian host signals which can be used to further define the unique equilibrium that exists between pathogenic leptospires and their reservoir host of infection.

Keywords: Leptospira, spirochetes, proteomics, DIGE, post-translational modifications

\section{INTRODUCTION}

Pathogenic species of Leptospira cause leptospirosis, a bacterial zoonotic disease with a global distribution affecting over one million people annually (Costa et al., 2015). Leptospires colonize renal tubules and are excreted in urine from reservoir hosts of infection. Contact with contaminated urine or water sources can result in infection via breaches of the skin and/or mucosal surfaces and disseminate haematogenously, causing a range of clinical symptoms from mild fever, to icteric Weil's disease and pulmonary hemorrhage syndrome. Mortality rates range from 10 to $70 \%$ depending on disease severity (McBride et al., 2005). In developed countries, leptospirosis is primarily a recreational disease, an occupational disease of farm workers, veterinarians, and slaughter plant workers, and in returning travelers. In developing countries, it is a socioeconomic disease perpetuated by rapid urbanization, rodent infestation, and transmission via contaminated water sources associated with limited infrastructures and severe weather events. Both rodents and domestic farm animal species serve as reservoir hosts of infection and sources of disease transmission to humans.

A large body of work has demonstrated that leptospires regulate and modify gene expression in response to environmental cues, as encountered during disease transmission, including changes in temperature (Lo et al., 2006; Qin et al., 2006; Matsunaga et al., 2013), osmolarity (Matsunaga et al., 2007), concentration of iron (Lo et al., 2010), the presence of serum (Patarakul et al., 2010), and interaction with macrophages (Xue et al., 2010). However, since leptospires are not readily amenable to genetic manipulation, the functional and biological significance of these transcriptomic changes are unclear (Adler et al., 2011; Picardeau, 2015). There often is limited correlation between gene and protein expression by leptospires (Lo et al., 2009) but it is clear that the protein profiles of pathogenic leptospires also are regulated in response to environmental cues encountered during host infection (e.g., in response to temperature and iron depletion; Nally et al., 2001a,b; Cullen et al., 2002; Eshghi et al., 2009). More recently, it was shown that protein expression, in response to changing environmental conditions, can be modified further by specific post-translational modifications (PTM; Eshghi et al., 2012). Indeed, both saprophytic and pathogenic leptospires have comprehensive bio-systems to modify proteins (Cao et al., 2010; Schmidt et al., 2011; Stewart et al., 2016). Recently, 32 phosphorylated, 46 acetylated, and 155 methylated proteins were identified that not only confirmed multiple modifications in prokaryotes, but also suggests that L. interrogans shares significant similarities with protein modification systems in eukaryotes (Cao et al., 2010). The surface-exposed outer membrane protein, OmpL32, undergoes differential methylation of glutamic acid residues in response to modifying in vitro growth conditions that emulate those encountered during mammalian host infection (Eshghi et al., 2012). In addition, L. interrogans can utilize endogenous biosynthetic pathways to elaborate surface structures containing sialic acids and related nonulosonic acids (Ricaldi et al., 2012b). Finally, the detection of PTM on lysine residues within LipL32 from in vivo-isolated L. interrogans implies that the infection-generated modification of leptospiral proteins may have a biologically relevant function during the course of infection (Witchell et al., 2014).

The paucibacillary nature of spirochetal infections, combined with the challenges associated with acquiring pathogens free from contaminating host proteins, makes the study of these bacteria in a mammalian host-adapted state inherently difficult. As an alternative approach, we developed a novel animal model in which leptospires are cultivated in a dialysis membrane chambers (DMCs) implanted within the peritoneal cavity of rats, where they are exposed to some of the environmental cues encountered during host infection (Caimano et al., 2014). This strategy has been applied successfully to compare the transcriptome of L. interrogans cultivated within DMCs with that of leptospires grown under standard in vitro conditions. In addition to determining the relative expression levels of "core" housekeeping genes under both growth conditions, we identified 166 genes that were differentially-expressed at the mRNA level by L. interrogans in response to mammalian host signals (Caimano et al., 2014).

In the current study, we applied the DMC model to compare the proteome of in vivo-derived leptospires with that of leptospires cultivated in vitro at $30^{\circ} \mathrm{C}$ or $37^{\circ} \mathrm{C}$ by 2 -dimensional difference in-gel electrophoresis (2-D DIGE). Our analysis indicates that the abundance of leptospiral proteins is modulated in response to mammalian host signals, and not temperature alone. In addition, we confirm that in several proteins there is a change in the presence of the PTM trimethyllysine and acetyllysine in response to environmental cues encountered during persistent renal colonization in a reservoir host of infection. These results provide novel insights into the proteome, including PTM, in response to mammalian host signals, which can be used to further define the unique equilibrium that exists between pathogenic leptospires and their reservoir host of infection.

\section{MATERIALS AND METHODS \\ In vitro-Cultivated Bacteria}

Virulent low-passage Leptospira interrogans serovar Copenhageni strain Fiocruz L1-130, kindly provided by 
Dr. David Haake (UCLA), was cultivated in vitro under standard static conditions for $8-9$ days at 30 or $37^{\circ} \mathrm{C}$ in EMJH medium supplemented with $1 \%$ rabbit serum (Pel-Freez Biologicals, Rogers, AR) with $100 \mu \mathrm{g} / \mathrm{ml}$ 5-fluorouracil. Cultures were grown to late logarithmic phase $\left(1-3 \times 10^{8}\right.$ per ml). Virulent low-passage L. interrogans serogroup Icterohaemorrhagiae strain RJ19115 was cultivated under standard static conditions at $30^{\circ} \mathrm{C}$ in EMJH medium until late logarithmic phase $\left(1-3 \times 10^{8}\right.$ per $\mathrm{ml})$.

\section{Dialysis Membrane Chamber (DMC)-Cultivated Bacteria}

All animal experimentation was conducted in accordance with protocols as reviewed and approved by the University of Connecticut Health Center Institutional Animal Care and Use Committee. To obtain mammalian host-adapted organisms, virulent low-passage $L$. interrogans serovar Copenhageni strain Fiocruz L1-130 was cultivated in DMCs as previously described (Caimano et al., 2014; Grassmann et al., 2015). In brief, DMCs were prepared with $8-10 \mathrm{ml}$ of EMJH medium [supplemented with $10 \%$ vaccine-grade bovine serum albumin (EMD Millipore, Billerica, MA) to maintain osmotic pressure] at a starting inoculum of $10^{4}$ organisms per ml. Using strict aseptic technique, each DMC was implanted into the peritoneal cavity of an anesthetized female Sprague-Dawley rat (Harlan). Approximately 9-10 days later, DMCs were explanted and the quality of leptospires evaluated for motility and density (1$3 \times 10^{8}$ leptospires per $\mathrm{ml}$ ) by dark field microscopy using a Petroff-Hausser counting chamber (Hausser Scientific Co., Horsham, PA).

\section{Urinary Derived Leptospires}

All animal experimentation was conducted in accordance with protocols as reviewed and approved by the Animal Care \& Use Committee at the National Animal Disease Center, and as approved by USDA Institutional guidelines. Urinary derived leptospires were collected from experimentally infected rats as previously described with slight modification (Monahan et al., 2008; Bonilla-Santiago and Nally, 2011). Male SpragueDawley rats (Harlan) of $\sim 5$ weeks of age were experimentally infected with $1 \times 10^{7}$ L. interrogans strain RJ19115 by intraperitoneal injection, a stain of $L$. interrogans serogroup Icterohaemorrhagiae which results in significant numbers of leptospires excreted in urine from colonized renal tubules. At 2 weeks post-infection (Rojas et al., 2010), rats were housed overnight in metabolism cages and urine collected directly into a $50 \mathrm{ml}$ conical tube containing $0.5 \mathrm{ml}$ Urine preservative (Norgen Biotek Corp). Urine samples were centrifuged at $4^{\circ} \mathrm{C}$, $1,000 \times \mathrm{g}$, for $5 \mathrm{~min}$ to remove excess debris. Supernatants were then centrifuged at $6,100 \times \mathrm{g}, 4^{\circ} \mathrm{C}$ for $60 \mathrm{~min}$ to collect urinary derived leptospires. Pellets were resuspended in $1 \mathrm{ml}$ ice-cold $10 \mathrm{mM}$ Tris-Cl, $1 \mathrm{mM}$ EDTA, transferred to a microfuge tube and collected by centrifugation at $12,000 \times \mathrm{g}$, $4^{\circ} \mathrm{C}$ for $30 \mathrm{~min}$. Samples were frozen at $-20^{\circ} \mathrm{C}$ until analysis.

\section{2-Dimensional Fluorescence Difference In-Gel Electrophoresis (2-D DIGE)}

2-D DIGE was performed on 18 biological replicates of L. interrogans serovar Copenhageni strain Fiocruz L1-130 comprising 6 biological replicates of leptospires cultivated at $30^{\circ} \mathrm{C}, 6$ biological replicates of leptospires cultivated at $37^{\circ} \mathrm{C}$ and 6 biological replicates of leptospires cultivated in DMCs. In vitro- and DMC-cultivated leptospires were harvested at late logarithmic phase by centrifugation, washed twice with TE buffer (10 mM Tris-Cl, $1 \mathrm{mM}$ EDTA, $\mathrm{pH}$ 7.4) and resuspended in solubilization buffer (7 M Urea, $2 \mathrm{M}$ Thiourea and 1\% ASB14) as previously described (Caimano et al., 2014). Protein concentrations were determined using the DC protein assay kit (Bio-Rad) as per manufacturer's instructions. An internal standard was prepared using a mixture of equal amounts of all 18 replicate samples included in the analysis. This internal standard was included in all gels to allow normalization of each independent gel and cross-gel comparison of each spot's density. 2-D DIGE was performed as previously described (Schuller et al., 2015) using $24 \mathrm{~cm}$ IPG strips pH 3-7 NL. Labeled samples were mixed according to the experimental design (Table 1) and the volume adjusted to $150 \mu$ l with rehydration buffer comprising $7 \mathrm{M}$ Urea, $2 \mathrm{M}$ Thiourea, 0.5\% (w/v) CHAPS and $2 \%(\mathrm{v} / \mathrm{v})$ ampholytes. After an overnight rehydration of the strips in $450 \mu \mathrm{l}$ of Destreak Rehydration Solution (GE Healthcare) complemented with $2 \%$ ampholytes, the samples were cuploaded and focused to reach a total of $75 \mathrm{kVh}(150 \mathrm{~V}$ for $3 \mathrm{~h}$, $300 \mathrm{~V}$ for $3 \mathrm{~h}$, a gradient to $1,000 \mathrm{~V}$ over $6 \mathrm{~h}$, a gradient to 10,000 $\mathrm{V}$ over $3 \mathrm{~h}$, and 10,000 $\mathrm{V}$ for $6.25 \mathrm{~h}$ ). The second dimension was carried out on an HPE system with large $12 \%$ non-fluorescent gels (Serva) following manufacturer's instructions.

\section{Image Acquisition and Analysis}

Gels were scanned using the Typhoon ${ }^{\circledR}$ FLA 9500 (GE Healthcare, Buckinghamshire, UK) as per manufacturer's instructions. Gels were analyzed with the Decyder version 7.0. Spot volumes were compared between samples derived from leptospires cultivated at $30^{\circ} \mathrm{C}, 37^{\circ} \mathrm{C}$ or in DMCs. For each spot, the ratio between conditions is calculated; when the ratio is above one, the fold change equals the ratio and if the ratio is

TABLE 1 | 2-D DIGE experimental design.

\begin{tabular}{llll}
\hline Gel \# & Cy3 & Cy5 & Cy2 \\
\hline 1 & IV37-Sample 2 & DMC-Sample 1 & Internal standard \\
2 & IV30-Sample 9 & IV37-Sample 7 & Internal standard \\
3 & DMC-Sample 2 & IV30-Sample 3 & Internal standard \\
4 & IV30-Sample 1 & DMC-Sample 5 & Internal standard \\
5 & IV37-Sample 1 & IV30-Sample 8 & Internal standard \\
6 & DMC-Sample 3 & IV37-Sample 9 & Internal standard \\
7 & IV37-Sample 8 & DMC-Sample 7 & Internal standard \\
8 & IV30-Sample 2 & IV37-Sample 3 & Internal standard \\
9 & DMC-Sample 6 & IV30-Sample 7 & Internal standard
\end{tabular}

Leptospires were cultured under in vitro conditions at $30^{\circ} \mathrm{C}$ (IV3O) or $37^{\circ} \mathrm{C}$ (IV37) and compared with leptospires cultured in dialysis membrane chambers (DMC) as described. 
below 1 , the fold change is given as $-(1 /$ ratio). Statistically significantly expressed protein spots were defined as having a $t$-test $p<0.05$ and a fold change of $>1.25$ or $<-1.25$ (Supplementary Table 1). Spots not meeting these statistical criteria were considered non-differentially expressed.

\section{Protein Digestion and Identification}

Spots of interest were picked using an Ettan spot picker (GE Healthcare) and digested with a fully automated Evo 2 workstation (Tecan). In brief, excised spots are washed and the proteins reduced with DTT and alkylated with iodoacetamide. After removal of excess salts, proteins were digested for $6 \mathrm{~h}$ at $37^{\circ} \mathrm{C}$ with $40 \mathrm{ng}$ of trypsin in $50 \mathrm{mM}$ ammonium carbonate (TrypsinGold, Promega). After digestion, peptides were extracted from the gel pieces, the extracts dried and spotted onto a MALDI plate. Mass spectra were acquired using a MALDI-TOFTOF mass spectrometer (Sciex 5800) and after the acquisition of a MS spectrum, the 10 highest peaks (excluding known contaminants) are selected for fragmentation. The MS-spectrum and the $10 \mathrm{MS} / \mathrm{MS}$ spectra are grouped in the database search with an in-house MASCOT engine (version 2.3, Matrix Science, matrixscience.com, London, UK). The primary database searched was the "L. interrogans serovar Copenhageni str. Fiocruz L1-130" database, downloaded on the 6th of February 2014 from NCBI (txid267671) and containing 7,818 sequences. When high-quality spectra were not matched during this primary search, they were individually resubmitted to a search against the entire NCBInr database (downloaded on the 23rd of September 2013 and containing 32,770,904 sequences). This resulted in the identification of bovine serum albumin (BSA) in some of the spots (Supplementary Table 2), a common contaminant due to the high concentration of BSA in the EMJH used for DMCs. The following parameters were used for the database searches: carbamidomethyl (C) as fixed modification; dioxidation (W), oxidation (M, W), and Trp to kynurenin (W) as variable modifications; peptide mass tolerance of $100 \mathrm{ppm}$, fragment mass tolerance of $0.5 \mathrm{Da}$; Trypsin as enzyme with a maximum of 2 missed cleavages. Compliant with minimal requirements for protein identification, no identifications purely based on the MS spectra were accepted. In addition to the requirement that the protein score had to be above the $p<0.05$ threshold, only protein identifications supported by at least two peptides with a score above the identity threshold for individual MS/MS spectra $(p<0.05)$ specified by MASCOT were accepted. Finally, all identifications were manually validated as previously described (Printz et al., 2013) and precursors not automatically selected were fragmented to increase the sequence coverage or to identify eventual co-migrating proteins. For this validation, the list of matched peptides was compared to the MS spectrum and in cases where high-intensity peaks were not matched to the identified protein secondary database, searches were performed. If these secondary searches resulted in the identification of a second protein, the spot was excluded from biological interpretation. Performing these secondary searches, and allowing the presence of semi-tryptic peptides during the database search, resulted in the identification of processed proteins. Further validation of close-to-threshold peptide identifications were done by looking at specific spectral features. Since the different oxidized forms of tryptophan are always found together, the identification of a peptide containing one of these oxidized forms was validated by looking at the presence of peaks corresponding to the same peptide with the other oxidation products of this residue (Trp; $\operatorname{Trp}+4 \mathrm{Da}=$ kynurenin, $\operatorname{Trp}+16 \mathrm{Da}=$ oxidized Trp; Trp +32 Da = N-formylkynurenin). Other easy-to-recognize spectral features that were looked at include the presence of a peak corresponding to the C-terminal arginine and the presence of the neutral loss of $64 \mathrm{Da}$ from peptides containing oxidized methionine. Furthermore, spectral characteristics related to the presence of the certain residues (most notably proline and aspartic acid) were analyzed (Breci et al., 2003; Paizs and Suhai, 2005). Similar for the presence of the amino acid glutamine at the $\mathrm{N}$-terminus of a peptide that is generally accompanied with the same peptide at $-17 \mathrm{Da}$ due to the formation of pyro-glutamic acid Functional annotation for proteins of unknown function was performed using the InterProScan tool (Jones et al., 2014; Finn et al., 2017). The mass spectrometry proteomics data have been deposited to the ProteomeXchange Consortium via the PRIDE (Vizcaíno et al., 2014) partner repository with the dataset identifier PXD006995.

\section{Immunoblotting}

Two-dimensional (2-D) gel electrophoresis was performed using $7 \mathrm{~cm}$ strips ( $\mathrm{pH} \mathrm{4-7)}$ as previously described, using indicated amounts of IV30, DMC or rat urine isolated leptospires. For immunoblotting, samples were transferred to Immobilon-P transfer membrane (Millipore, Bedford, MA) and blocked with $5 \%(\mathrm{w} / \mathrm{v})$ non-fat dried milk in phosphate-buffered saline- $0.1 \%$ (v/v) Tween 20 (PBS-T). Membranes were individually incubated with indicated antisera (anti-LipL32 or anti-LipL41) at 1:2,500 in PBS-T for $1 \mathrm{~h}$ at room temperature, or anti-trimethyllysine or anti-acetyllysine (PTM Biolabs, IL, U.S.A.) at 1:1,000 in $1 \%(\mathrm{w} / \mathrm{v})$ non-fat dried milk in PBS-T overnight at $4{ }^{\circ} \mathrm{C}$, followed by incubation with horseradish-peroxidase anti-rabbit immunoglobulin G conjugate. Bound conjugates were detected using the SuperSignal WestPico substrate (Pierce) or Clarity Western ECL substrate (BioRad) and images acquired using a UVP Biospectrum-AC w/Bio Chemi camera (Cambridge, United Kingdom) or Bio-Rad ChemiDoc MP imaging system. The specificity of the PTM-specific antibodies has been previously reported (Chu et al., 2016; Hong et al., 2016).

\section{RESULTS}

\section{Pathogenic Leptospires Modify Protein Abundance in Response to Mammalian Host Signals}

Total protein profiles of leptospires cultivated in vitro at $30^{\circ} \mathrm{C}$ (IV30), $37^{\circ} \mathrm{C}$ (IV37) or in DMCs were compared by $2 \mathrm{D}$ DIGE over a $\mathrm{pH}$ range of 3-7 NL, Figure 1. Of 1735 protein spots aligned across 9 gels comprising 27 scans, 202 protein spots were determined to be differentially expressed $(p<0.05$, fold change $>1.25$ or $<-1.25$ ) across the three conditions (Supplementary Table 1). When DMC-cultivated leptospires 


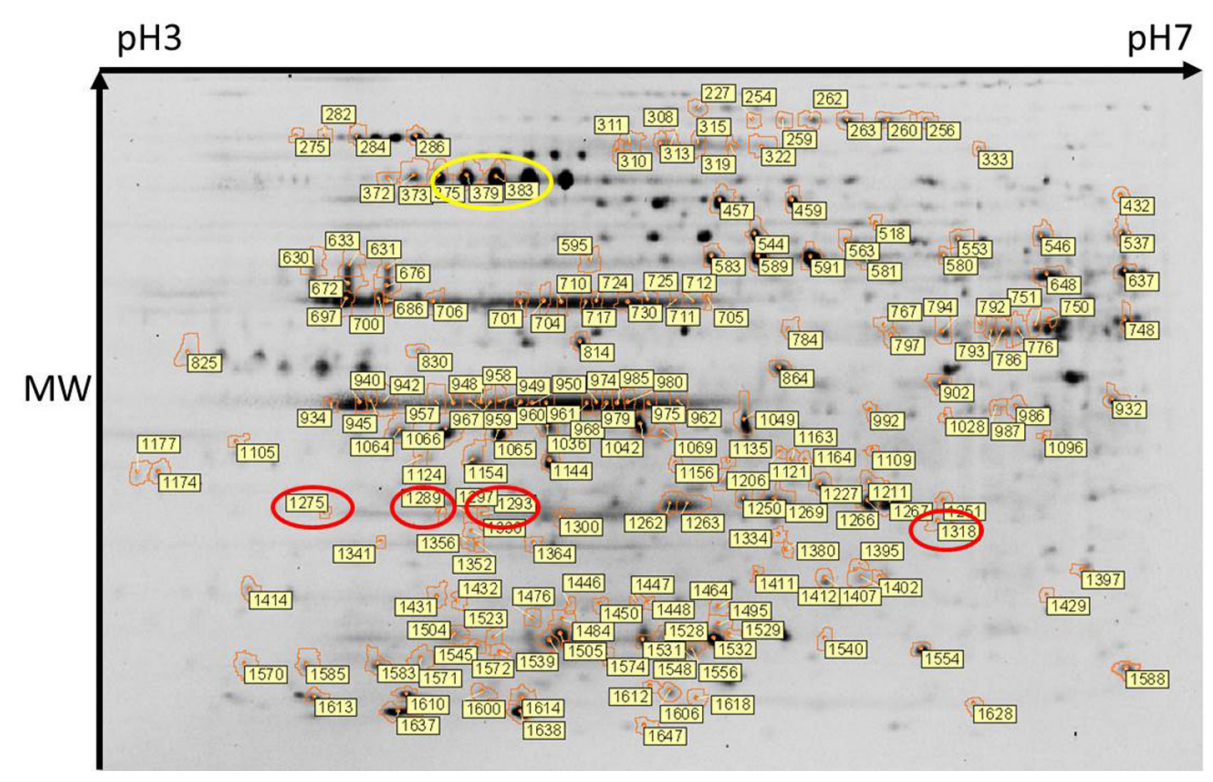

FIGURE 1 | Two-dimensional gel electrophoresis of leptospires. Composite image of protein spots detected across all 9 gels and in which 1735 protein spots were aligned. Of these, 202 protein spots were determined to be differentially expressed (DE) $(p<0.05)$. DE protein spots, and their identifier (as listed in Supplementary Tables 1, 2) are indicated. Protein isoforms of the differentially expressed Loa22 and GroEL are circled in red and yellow respectively. An unmarked version of the stained gel is presented in Supplementary Figure $\mathbf{1}$.

were compared to IV30 leptospires, 187 spots were of different intensity ( $p<0.05)$ : of these, 43 were increased in DMCs whilst 144 were decreased (Supplementary Table 1). Similarly, when DMC-cultivated leptospires were compared to IV37cultivated leptospires, 181 protein spots were differentially expressed ( $p<0.05$, fold change $>1.25$ or $<-1.25$ ): 38 spots were increased in DMCs and 143 decreased. The majority of differentially expressed proteins are common to each group, Figure 2.

Comparison of IV30- and IV37-cultivated leptospires identified only 18 protein spots of significant different intensity $(p<0.05$, fold change $>1.25$ or $<-1.25)$ : seven were increased at $37^{\circ} \mathrm{C}$ and 11 were increased at $30^{\circ} \mathrm{C}$.

\section{Protein Identification}

Spots of interest, as labeled in Figure 1, were excised from 2-D DIGE gel \#4 for identification of proteins by mass spectrometry. Only those protein spots that had one single significant protein identification are discussed below. All protein identifications are provided in Supplementary Tables 1, 2. Proteins present at a higher abundance in DMCs compared to in vitro-cultivated leptospires included the known virulence factor Loa22 (OmpAlike domain membrane protein), previously shown to be of higher abundance in intact motile leptospires purified from the liver of experimentally-infected guinea pigs, or in leptospires excreted from the kidney of persistently infected rats (Nally et al., 2007b, 2011); four isoforms of Loa22 (protein spots 1,318, 1,275, 1,293, and 1,289, circled in Figure 1, Table 2, and Supplementary Tables 1, 2) were increased 1.9-, 1.75-, 1.58- and 1.44-fold in DMCs respectively, compared to IV30 leptospires.

\section{A}

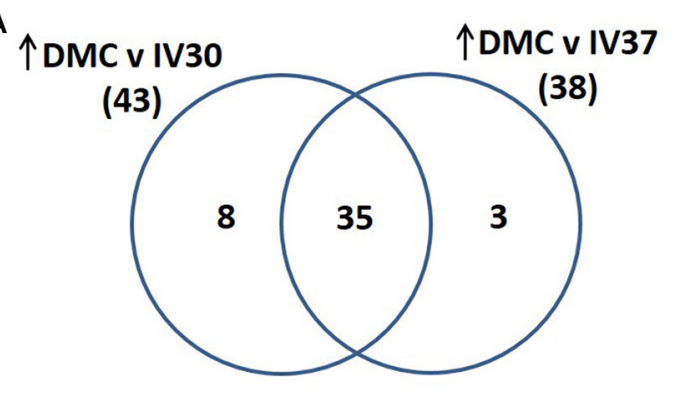

B

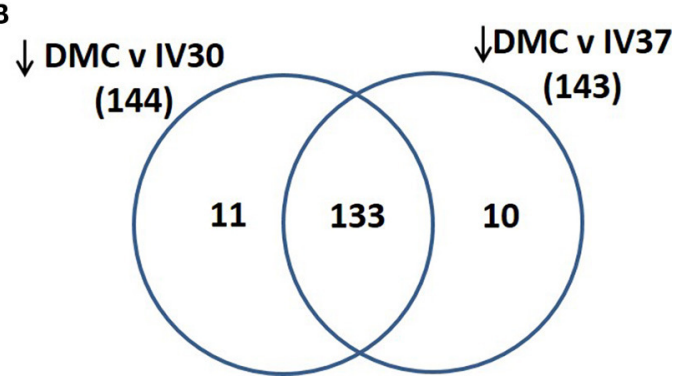

FIGURE 2 | Venn diagram illustrating the numbers of proteins that were identified as (A) increased in abundance in DMC compared to IV30 or IV37 leptospires or (B) decreased in abundance in DMC compared to IV30 or IV37 leptospires.

Similarly, the chaperone protein GroEL has also been shown to be increased in expression by leptospires excreted in urine from experimentally infected rats (Nally et al., 2011): three isoforms 
TABLE 2 | Proteins more abundant $(p<0.05$, fold > 1.25) in DMC-cultivated leptospires compared to IV30-cultivated leptospires.

\begin{tabular}{|c|c|c|c|c|c|}
\hline Protein spot number & $p$-value & Av. ratio & $\begin{array}{l}\text { GI accession number } \\
\text { (Accession number) }\end{array}$ & Protein name (Locus tag) & $\begin{array}{l}\text { InterPro scan analysis } \\
\text { (for proteins of unknown } \\
\text { function) }\end{array}$ \\
\hline 313 & 0.00057 & 7.05 & $\begin{array}{l}\text { gi|45602612 } \\
\text { (AAS72087.1) }\end{array}$ & $\begin{array}{l}\text { methylmalonyl-CoA mutase } \\
\text { (LIC_20058) }\end{array}$ & \\
\hline 992,987 & $\begin{array}{l}0.000076 \\
0.000011\end{array}$ & $\begin{array}{l}4.49 \\
3.71\end{array}$ & $\begin{array}{l}\text { gi|45601096 } \\
\text { (AAS70579.1) }\end{array}$ & $\begin{array}{l}\text { succinate dehydrogenase } \\
\text { iron-sulfur subunit } \\
\text { (LIC_12003) }\end{array}$ & \\
\hline $375,383,379$ & $\begin{array}{l}0.0012,0.017 \\
0.0015\end{array}$ & $3.95,2.59,2.48$ & $\begin{array}{l}\text { gi|45600451 } \\
\text { (AAS69936.1) }\end{array}$ & $\begin{array}{l}\text { GroEL } \\
(\text { LIC_11335) }\end{array}$ & \\
\hline 1,028 & 0.0046 & 3.53 & $\begin{array}{l}\text { gi|45602037 } \\
\text { (AAS71516.1) }\end{array}$ & $\begin{array}{l}\text { LipL41 } \\
\text { (LIC_12966) }\end{array}$ & $\begin{array}{l}\text { Tetratricopeptide repeat } \\
\text { (TPR) domain }\end{array}$ \\
\hline 1,164 & 0.013 & 3.09 & $\begin{array}{l}\text { gi|45601580 } \\
\text { (AAS71060.1) }\end{array}$ & $\begin{array}{l}\text { 3-hydroxybutyryl-CoA } \\
\text { dehydratase } \\
\text { (LIC_12495) }\end{array}$ & \\
\hline 282,284 & $0.00071,0.011$ & $2.78,2.07$ & $\begin{array}{l}\text { gi|45599657 } \\
\text { (AAS69145.1) }\end{array}$ & $\begin{array}{l}\text { DnaK } \\
(\text { LIC_10524) }\end{array}$ & \\
\hline $1,446,1445$ & $0.0052,0.045$ & $\begin{array}{l}2.4 \\
1.75\end{array}$ & $\begin{array}{l}\text { gil45600006 } \\
\text { (AAS69493.1) }\end{array}$ & $\begin{array}{l}\text { putative lipoprotein } \\
\text { (LIC_10879) }\end{array}$ & None predicted \\
\hline 518 & 0.039 & 2.02 & $\begin{array}{l}\text { gi|45601495 } \\
\text { (AAS70976.1) }\end{array}$ & $\begin{array}{l}\text { putative glutamine } \\
\text { synthetase protein } \\
\text { (LIC_12407) }\end{array}$ & \\
\hline $\begin{array}{l}1,318,1,275,1,293 \\
1,289\end{array}$ & $\begin{array}{l}0.0037 \\
0.0098,0.026 \\
0.024\end{array}$ & $\begin{array}{l}1.9 \\
1.75,1.58,1.44\end{array}$ & $\begin{array}{l}\text { gi|45599329 } \\
\text { (AAS68819.1) }\end{array}$ & $\begin{array}{l}\text { Loa } 22 \text { (peptidoglycan } \\
\text { associated cytoplasmic } \\
\text { membrane protein) } \\
\text { (LIC_10191) }\end{array}$ & OmpA-like domain \\
\hline
\end{tabular}

of GroEL (protein spots 375, 383, and 379, circled in Figure 1, Table 2, and Supplementary Tables 1, 2) were increased 3.95-, 2.59 ,- and 2.48-fold, respectively. These protein identifications serve as internal controls confirming the use of DMC-cultivated leptospires as a surrogate model for the characterization of protein expression by leptospires in response to mammalian host signals.

All the proteins that are of significant higher abundance in DMC-cultivated leptospires compared to in vitrocultivated controls (IV30) are provided in Table 2 and Supplementary Tables 1, 2. Similar results are obtained when DMC leptospires are compared against IV30 or IV37 leptospires, Figure 2. The cobalamin-dependent methylmalonylCoA mutase was identified as the single protein (spot 313) that was most increased (7.05-fold change) in DMC-cultivated leptospires relative to IV30 leptospires (and increased 6.19-fold relative to IV37 leptospires). Additional metabolic enzymes increased in DMCs include succinate dehydrogenase iron-sulfur subunit (spots 992 and 987; increased 4.49- and 3.71-fold, respectively), 3-hydroxybutyryl-CoA dehydratase (spot 1,164; increased 3.09-fold) and glutamine synthetase (spot 518; increased 2.2-fold). Multiple isoforms of the chaperone protein DnaK were also increased in DMC-cultivated leptospires, as well as protein isoforms of a putative lipoprotein (LIC10879). A single protein isoform of the outer membrane lipoprotein LipL41 was identified as being increased in DMC-cultivated leptospires but this isoform (spot 1028) has an unusual mass and $\mathrm{pI}$ compared to that typically observed for LipL41 (see 7 isoforms identified below). This indicates that the protein species in spot 1,028 is a degradation product of the LipL41 protein, which corresponds in molecular mass and $\mathrm{p} I$ to an isoform of LipL41 that was previously identified in $2-\mathrm{D}$ gels of leptospires cultivated at $37^{\circ} \mathrm{C}$ (Cullen et al., 2002).

Proteins found in higher amounts in samples from IV30compared to DMC-cultivated leptospires are provided in Table 3 and Supplementary Tables 1, 2. Similar results are obtained when DMC leptospires are compared against IV30 or IV37 leptospires, Figure 2. Two isoforms of the molecular cochaperone GroES (spots 1,638 and 1,637) were decreased in DMC-cultivated leptospires 12.47- and 9.45-fold, respectively. Two isoforms of the metabolic protein Elongation factor $\mathrm{Tu}$ (EF-Tu), which is hypothesized to be surface-exposed in leptospires and interact with both plasminogen and complement factor $\mathrm{H}$ (Wolff et al., 2013), were also decreased 10.7- and 2.81-fold, respectively. Three isoforms of peroxiredoxin (AhpC; spots $1,266,1,263, \& 1,262)$ were detected in lower amounts in DMC-cultivated leptospires, which is in contrast to the 5.96fold increase in DMC for the corresponding gene transcript observed by RNAseq (Caimano et al., 2014). Consistent with lower levels of AphC protein, the levels of two isoforms of dihydrolipoamide succinyltransferase (SucB) were also decreased in abundance; this protein has been shown to interact with AphC to support antioxidant defense in Mycobacterium tuberculosis (Bryk et al., 2002). Proteins predicted to play a role in cell shape were found in lower amounts in DMC-cultivated leptospires and include the rod-shape determining protein $\mathrm{MreB}$, cell shape determination protein LIC13483 and three isoforms of cell shape determination protein LIC12621. The expression of other 
TABLE 3 | Proteins less abundant $(p<0.05$, fold $>-1.25)$ in DMC-cultivated leptospires compared to IV30-cultivated leptospires.

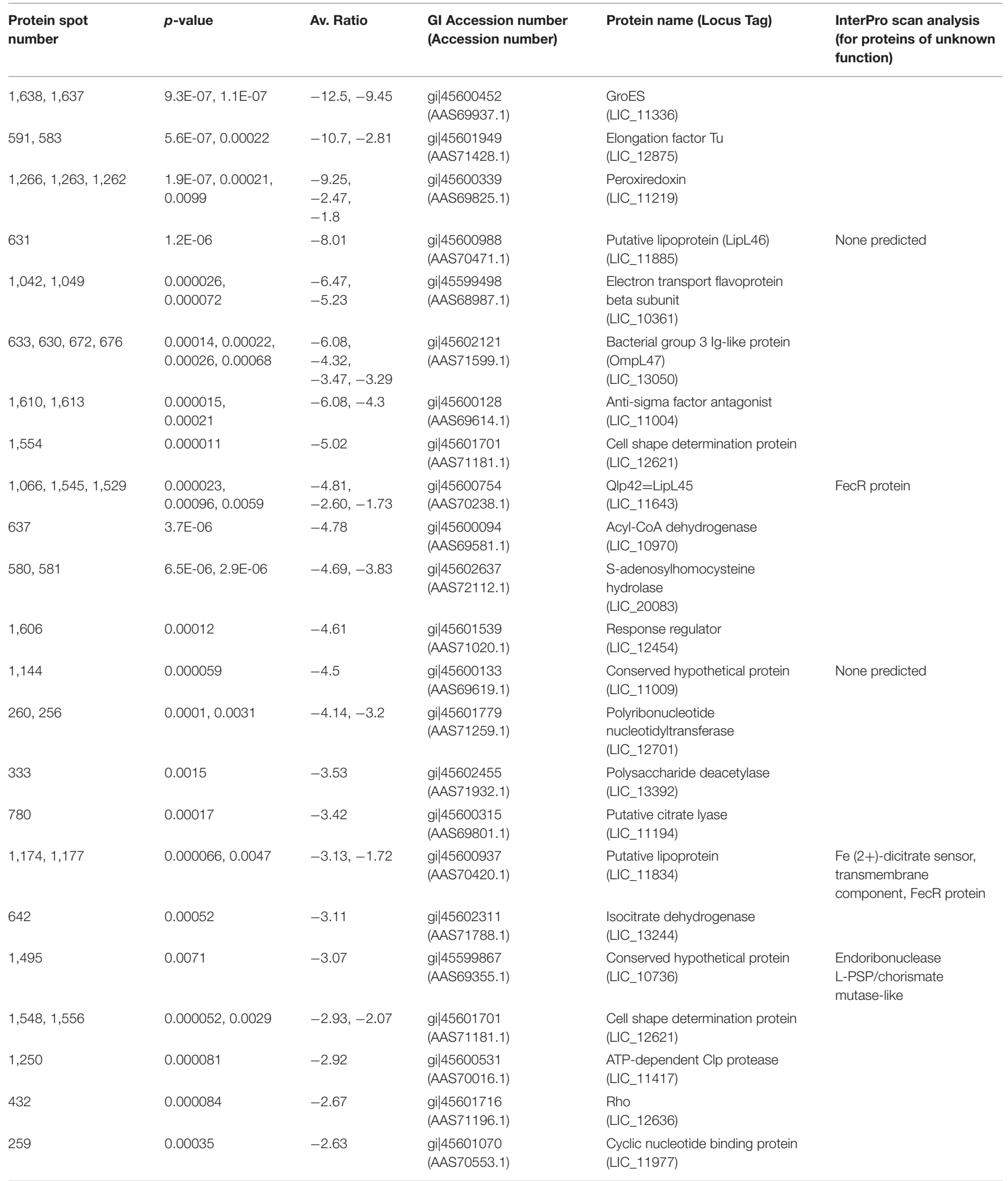


TABLE 3 | Continued

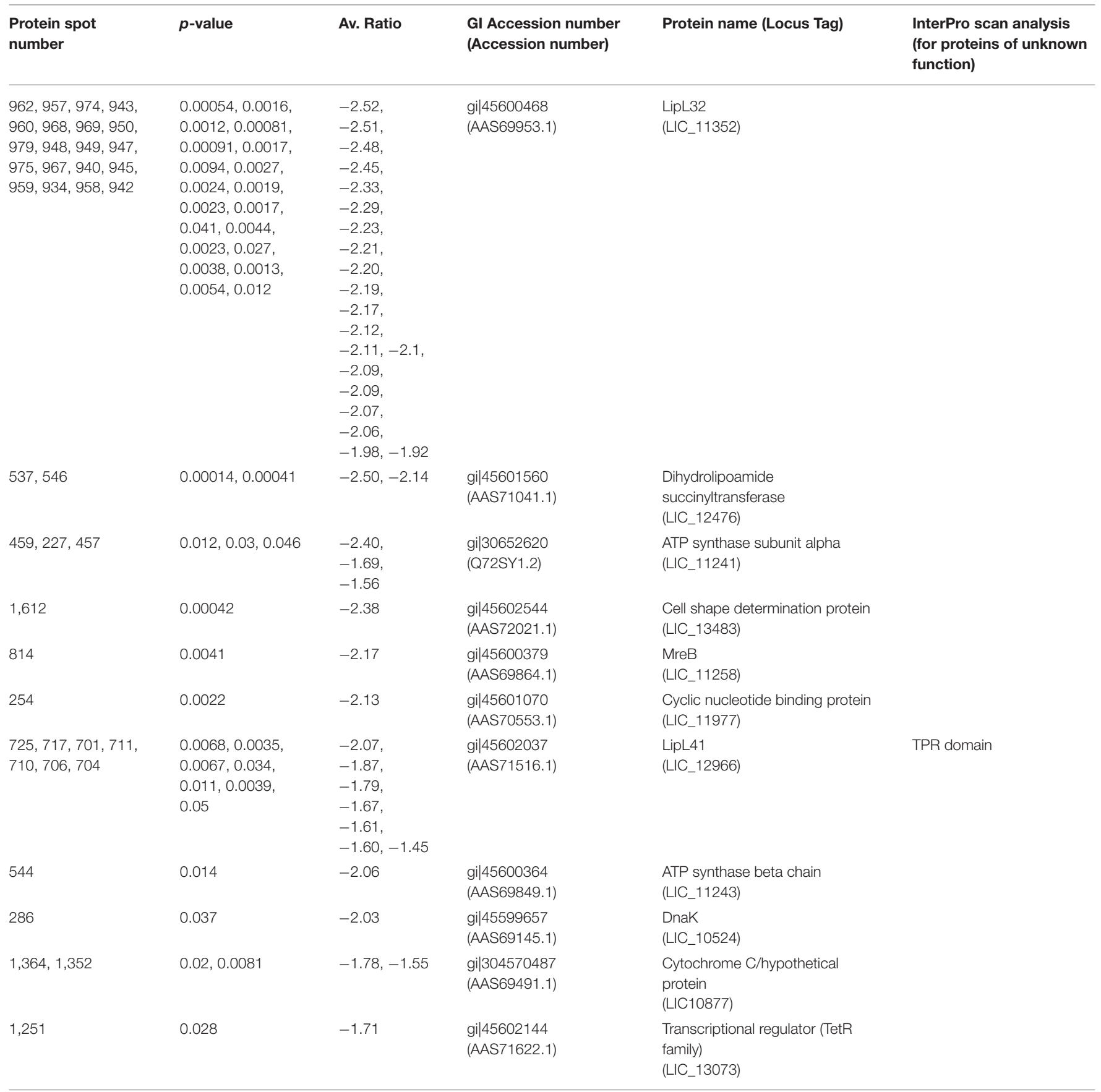

proteins predicted to be involved in a wide range of cell functions was also diminished in DMC leptospires including proteins involved in RNA transcription and degradation (LIC11004, LIC13073, LIC12701, \& LIC12636), amino acid metabolism (LIC20083, LIC13244, \$\& LIC10736), two component systems signal transduction systems (LIC12454 \& LIC11194) and energy storage (LIC11241 \& LIC11243).

The abundance of several known (or putative) outer membrane $(\mathrm{OM})$ proteins and lipoproteins and conserved hypothetical proteins were also down in DMC-cultivated leptospires including LipL46 (LIC11885), OmpL47 (LIC13050), Qlp42/LipL45 (LIC11643), LipL32 (LIC11352), and LipL41 (LIC12966). Of note, 20 isoforms of LipL32 were all down in DMC. Similarly, the intensity of 7 spots wherein LipL41 is identified was down. Collectively, the identification of multiple isoforms of LipL32 and LipL41 derived from DMC leptospires which were all shifted in the same direction on a 2-D gel prompted us to explore the possibility that this shift was mediated 
via PTM. However, analysis of MS-spectra of different spots wherein the same protein was identified failed to identify MS spectral features that could be identified as modified peptides, likely a reflection of the limited amounts of protein used in 2-D DIGE gels.

\section{Protein Post-translational Modifications}

Multiple protein species of a number of individual proteins were identified. This was exemplified by LipL32, the most abundant leptospiral outer membrane protein; 20 LipL32-isoforms were of lower abundance $(<-1.25$-fold, $p<0.05)$ in DMC leptospires (Table 3 and Supplementary Tables 1, 2). 2D-immunoblotting of DMC- and IV30-cultivated leptospires with LipL32-specific antiserum confirms reactivity with multiple protein isoforms, but results of immunoblot suggest that DMC- and IV30cultivated leptospires express roughly equivalent amounts of LipL32 (Figures 3A,B). However, a shift in the ratio between the isoforms at different isoelectric points is observed, as indicated by an arrow in Figures 3A,B.

Characterization of the intact mass of LipL32 derived from purified OM vesicles confirmed that proteoforms of LipL32 can differ in their fatty acid moieties that anchor this lipoprotein into the outer membrane (i.e., lipoforms; Nally et al., 2005). More recently, studies have demonstrated that PTM occur on lysine residues of LipL32 during renal excretion compared to in vitrocultivated controls (Witchell et al., 2014). Thus, we hypothesized that specific PTMs could account for, at least in part, the observed shift in $\mathrm{p} I$ of isoforms of LipL32 in DMC- compared to IV30cultivated leptospires as detected by 2 -D DIGE, and that such modifications are in response to environmental cues encountered during host infection.

To test this hypothesis, urinary derived leptospires were collected from experimentally infected rats for 2-D immunoblotting with antisera specific for the detection of defined protein PTM. Experimental infection of rats was performed with an alternative strain (strain RJ19115) to ensure that significant numbers of urinary derived leptospires could be collected for analysis by 2 -D immunoblot. Immunoblotting confirmed that several protein antigens from IV30 were reactive with anti-trimethyllysine (Figure 4A, arrows), which were not readily detected in rat urine isolated leptospires (Figure 4B). Reactive antigens include several isoforms with similar mass and $\mathrm{p} I$ to that of LipL32 (Figures 4C,D). Additionally, immunoblotting with antibody specific for the protein PTM acetyllysine provides further evidence for differential expression of PTM by leptospires excreted in urine compared to their in vitro-cultivated counterpart (Figures 5A,B).

\section{DISCUSSION}

The transcriptome and proteome of leptospires cultivated in vitro has been studied extensively. However, comparative analysis of the transcription and translation of leptospiral outer membrane proteins, in response to increased temperature, identified a large number of differences in protein profile without a corresponding change in transcript levels (Lo et al., 2009). These results highlight the need to characterize the contribution of post-transcriptional regulatory pathways to mammalian host adaption by pathogenic leptospires. We have used the DMC model to comprehensively identify gene expression of leptospires in vivo by RNA-seq (Caimano et al., 2014). In the current study, we applied the DMC model to identify proteins that are differentially abundant in response to mammalian host signals. Our analysis confirms that pathogenic leptospires modulate protein expression in response to growth in DMC. However, and similar to previous studies comparing differential expression of gene transcription and translation in leptospires (Lo et al., 2009), none of the identified differentially abundant proteins had equivalent differentially expressed gene transcripts (based on our published RNA-seq data; Caimano et al., 2014).

Pathogenic leptospires are highly fastidious bacteria which are typically cultured in albumin enriched media at $28-30^{\circ} \mathrm{C}$ (Zuerner, 2005). This is in stark contrast to conditions encountered during disease transmission; leptospires adapt to and replicate in the renal tubule of a reservoir host from which they are excreted via urine to survive in suitable
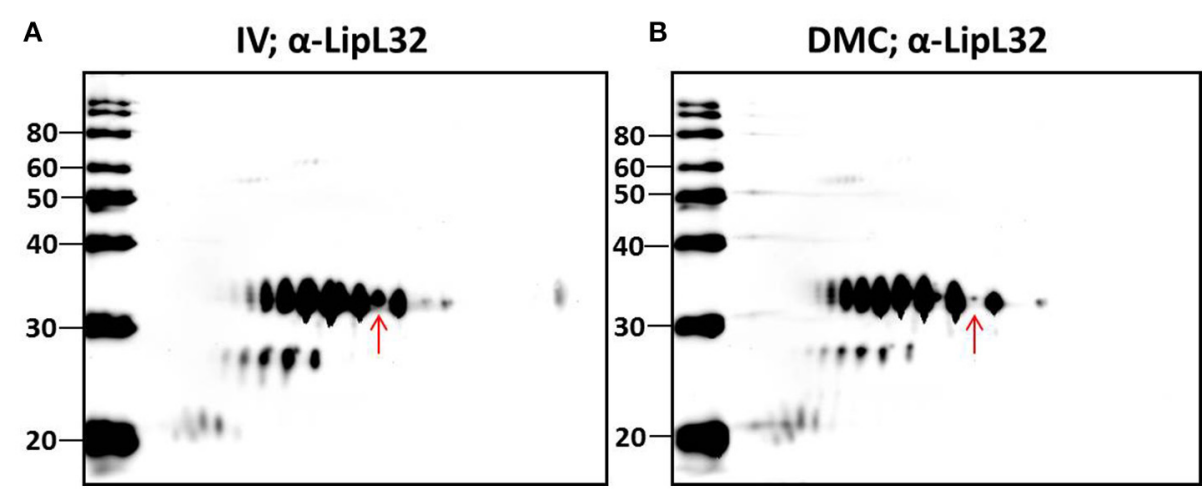

FIGURE 3 | 2-D Immunoblot analysis of (A) IV- and (B) DMC-cultivated leptospires. Approximately $10^{7}$ IV or DMC cultivated leptospires (strain Fiocruz L1-130) were separated by 2-D gel electrophoresis and probed with antiserum specific for LipL32. Red arrow indicates the same protein isoform in each immunoblot of LipL32 when immunoblots are overlaid. Molecular mass markers $(\mathrm{kDa})$ are indicated. 

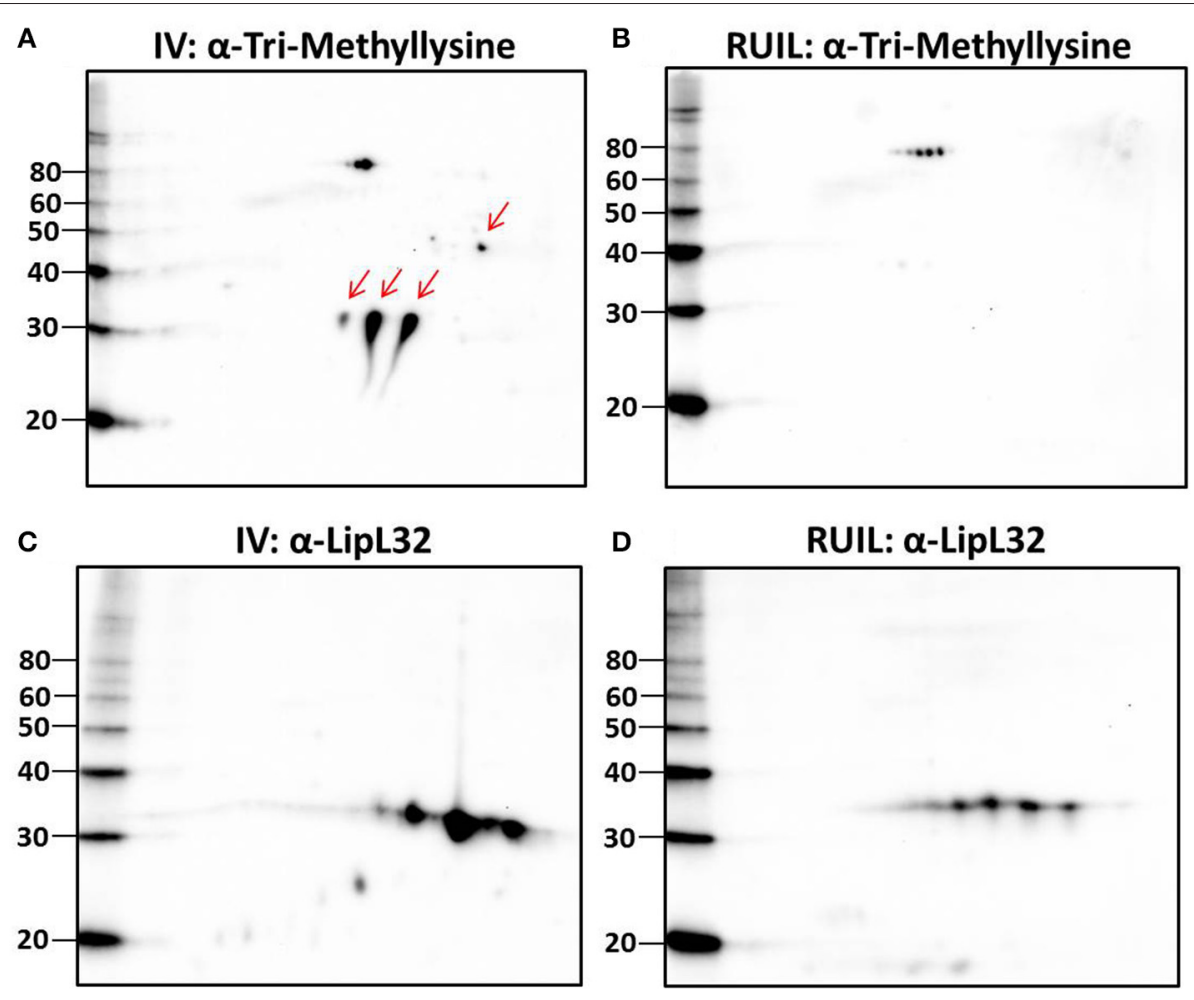

FIGURE 4 | 2-D Immunoblot analysis of IV and rat urine isolated leptospires. Approximately $2 \times 10^{7}$ IV30 (A,C) or rat urine isolated leptospires (RUIL) (Strain RJ19115) (B,D) were separated by 2-D gel electrophoresis (pH 4-7) and probed with antiserum specific for trimethyllysine (A,B) or antiserum specific for LipL32 (C,D) Arrows indicate antigens reactive with anti-trimethyllysine that are expressed by IV- but not DMC-cultivated leptospires. Molecular mass markers (kDa) are indicated.

moist environments. After host invasion, they disseminate haematogenously to multiple organs (Coutinho et al., 2014), and in particular, the kidney, to establish and maintain persistent infection (Bolin and Alt, 2001; Athanazio et al., 2008). To further understand pathogenic mechanisms of leptospirosis and identify gene expression pathways and regulatory mechanisms predicted to facilitate host infection, prior studies have relied on modification of in vitro growth conditions to emulate conditions encountered during disease transmission and within the mammal (Matsunaga et al., 2013). Since pathogenic leptospires are not readily amenable to targeted genetic manipulation, validation of gene encoded virulence factors is generally dependent on random mutagenesis (Murray et al., 2009). Such is the case for loa22, the first virulence factor of leptospires identified that satisfied molecular Koch's postulates (Ristow et al., 2007). However, transcript levels of loa22 do not change in response to temperature (Lo et al., 2006; Qin et al., 2006), osmolarity (Matsunaga et al., 2007), serum concentration (Patarakul et al., 2010) or growth in DMC (Caimano et al., 2014), but are down-regulated during interaction with macrophages (Xue et al., 2010). In contrast, the protein expression of Loa22 is significantly increased in leptospires extracted from the liver tissue of acutely infected guinea pigs (Nally et al., 2007b), and increased 2.1-fold in leptospires excreted from persistently infected rats (Monahan et al., 2008; Nally et al., 2011). In addition, levels of Loa22 are increased in leptospires cultivated in iron-depleted media and the presence of serum (Eshghi et al., 2009). Here, we report that multiple proteoforms of the Loa22 virulence factor and outer membrane protein are increased 1.9-, 1.75-, 1.58-, and 1.44-fold (spot 1,318, $1,275,1,293$, \& 1,289 , respectively) in response to mammalian host signals encountered by leptospires cultivated in DMC, a model system for the cultivation of leptospires in vivo, Figure 1.

Previously we have shown that the gene expression for peroxiredoxin $(a h p C)$ was increased 5.96-fold in DMC-cultivated leptospires compared to IV30 leptospires. This contrasts sharply with our current findings in which three protein isoforms of AhpC were decreased 9.25-, 2.47-, and 1.8-fold in DMC compared to IV30 leptospires, and in two isoforms decreased 6.26- and 2.01-fold in DMC compared to IV37 leptospires. Recent studies comparing leptospires cultivated at $37^{\circ} \mathrm{C}$ compared to $30^{\circ} \mathrm{C}$ demonstrated that $\mathrm{AhpC}$ is increased 1.6-fold without a corresponding increase in gene transcript (Lo et al., 2009). Collectively, these results suggest that AhpC is subject to, and as yet uncharacterized, post-transcriptional regulation. L. interrogans does not encode an $\mathrm{AhpF}$, the usual reducing partner for $\mathrm{AhpC}$. In $M$. tuberculosis, AhpC interacts with SucB (dihydrolipoamide succinyltransferase), which was detected at lower levels in DMC leptospires compared to IV30 leptospires ( -2.5 and -2.14 -fold) or compared to IV37 leptospires $(-2.49$ and -2.01 -fold). 
A
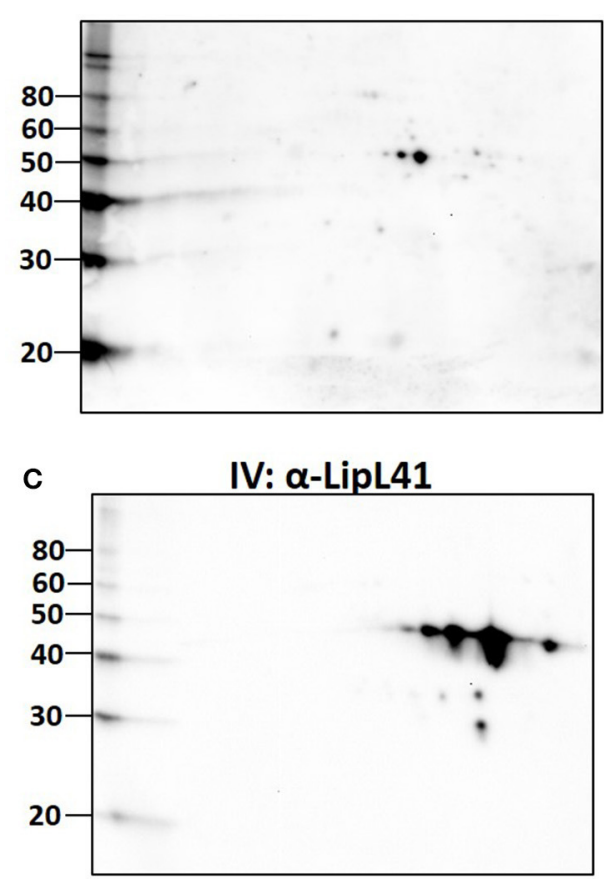

\section{B RUIL: $\alpha$-Acetyllysine}

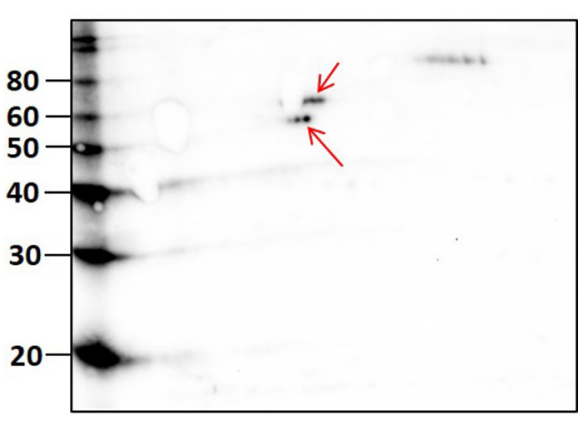

DUIL: $\alpha$-LipL41

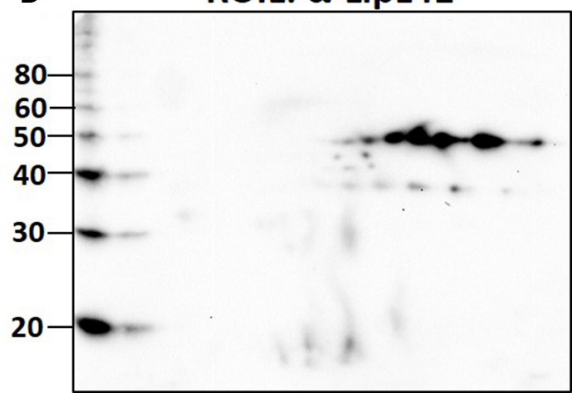

FIGURE 5 | 2-D Immunoblot analysis of in vitro $\left(30^{\circ} \mathrm{C}\right.$; IV) and rat urine isolated (RUIL) leptospires. Approximately $2 \times 10^{7}$ or Strain RJ19115 leptospires were separated by 2-D gel electrophoresis and probed with antiserum specific for acetyllysine (A,B) or LipL41 (C,D). Arrows indicate antigens reactive with anti-acetyllysine that are expressed by DMC- but not IV30-cultivated leptospires. Molecular mass markers (KDa) are indicated.

The cobalamin (vitamin $\mathrm{B}_{12}$ ) dependent methylmalonylCoA mutase was identified in spot 313 with a fold change of 7.05 and 6.19 in DMC-cultivated leptospires compared to IV30 or IV37 leptospires, respectively. This metabolic enzyme was also identified in spots 319 and 315 which were increased 10.48- and 6.8-fold respectively in DMC leptospires compared to IV30. Recently identified small non-coding RNAs include cobalamin riboswitches which are expressed by DMCcultivated leptospires (Ricaldi et al., 2012a; Caimano et al., 2014; Zhukova et al., 2017). These function as cis-regulatory elements in $5^{\prime}$-untranslated regions of vitamin $\mathrm{B}_{12}$-related genes, however their function remains to be determined. Comparative analysis of 20 species of Leptospira predicted that only pathogenic strains make cobalamin de novo from L-glutamate, suggesting that this process is critical in vivo, and that such autotrophy allows leptospires to infect mammals in the face of vitamin $B_{12}$ sequestration by the host (Fouts et al., 2016).

As a general trend, and similar to protein expression by leptospires cultivated at $37^{\circ} \mathrm{C}$ compared to $30^{\circ} \mathrm{C}$ (Lo et al., 2009), the abundance of many OM proteins was reduced in DMC compared to IV30 and IV37 leptospires. LipL46, a surface-exposed lipoprotein expressed during leptospiral dissemination in the mammalian host (Matsunaga et al., 2006), was downregulated 8.01- and 4.37-fold in DMC compared to IV30 and IV37 leptospires. No change in transcript levels for
lipL46 was observed in DMC or leptospires cultured at $37^{\circ} \mathrm{C}$ (Lo et al., 2006; Qin et al., 2006; Caimano et al., 2014), though expression of this gene has been shown to be downregulated when interacting with macrophages (Xue et al., 2010).

Four isoforms of OmpL47 (LIC13050) were 6.08-, 4.32-, 3.47-, and 3.29-fold lower in DMC leptospires compared to IV30 leptospires; similarly the same four isoforms were down 3.24-, 2.43-, 2.28-, and 2.3-fold when compared to IV37 leptospires. However, no difference was detected at the level of gene transcription by RNAseq (Caimano et al., 2014). The observed fold change of OmpL47 is similar to previous studies that demonstrated that OmpL47 is a temperatureregulated protein and of lower abundance in leptospires cultured at $37^{\circ} \mathrm{C}$ compared to those cultured at $30^{\circ} \mathrm{C}$, and with no corresponding change in gene expression (Lo et al., 2009). In agreement with this, our analysis indicates that temperature is an important environmental cue for the expression of OmpL47 since four isoforms (spots 633, 630, 672, and 676) were of lower abundance (1.88-, 1.78-, 1.52-, and 1.43-fold, respectively) when IV37- were compared only with IV30-cultivated leptospires (Supplementary Table 1). Nevertheless, OmpL47 is reported to be a surface exposed protein that binds skin and elastin and is expressed during infection (Eshghi et al., 2009; Pinne et al., 2010). OmpL47 has also been detected in cell culture supernatants so it's apparent down-regulation may be due to increased levels of secretion (Zeng et al., 2013; Eshghi et al., 2015). 
LipL45 was originally identified as Qlp42, the abundance of which was increased in leptospires cultivated at $37^{\circ} \mathrm{C}$ compared to $30^{\circ} \mathrm{C}$ without an apparent change in the levels of gene transcription (Nally et al., 2001a; Lo et al., 2009). In contrast to a predicted molecular mass of $39.8 \mathrm{kDa}$ for LipL45/Qlp42, the actual mass was measured as 24,811 and 26,461 Da consistent with a $30 \mathrm{kDa}$ doublet observed on sodium dodecyl sulfate-polyacrylamide gel electrophoresis gels and processing of the $\mathrm{N}$-terminus of the mature protein (Nally et al., 2001a, 2005; Matsunaga et al., 2002). We identified multiple isoforms of LipL45 that were detected at lower levels in DMC compared to IV30 or IV37 leptospires. InterproScan identified LipL45 as a FecR protein which is involved in the regulation of iron dicitrate transport. In the absence of citrate, FecR inactivates the probable RNA polymerase sigma factor, FecI. FecR is likely a sensor for periplasmic iron dicitrate. Gene expression levels of lipL45 are down over 5fold during interaction with macrophages (Xue et al., 2010). LIC11834, which encodes Lsa33, was also predicted to be a FecR protein and was similarly down in DMC leptospires. This protein binds laminin and activates plasminogen, and is predicted to be surface exposed (Domingos et al., 2012). Gene expression of $l s a 33$ is down-regulated -2.03-fold at physiological osmolarity compared with low osmolarity (Matsunaga et al., 2007).

Unexpectedly, 20 protein isoforms of LipL32 were uniformly identified by 2-D DIGE as differentially expressed. Similarly, 7 isoforms of LipL41 were differentially expressed. Both LipL32 and LipL41 are constitutively expressed under a wide range of in vitro and in vivo conditions, though their functions have yet to be determined (Shang et al., 1996; Haake et al., 2000). LipL32 and LipL41 are outer membrane proteins and multiple isoforms are readily observed in 2-D gels of whole or OM enriched leptospires, either by direct protein staining or immunoblotting (Nally et al., 2005, 2007b), as illustrated by the detection of LipL32 in DMC or IV30 leptospires (Figures 3A,B). Collectively, the apparent shift in $\mathrm{p} I$ of each of these isoforms could be explained, in part, by PTM. Multiple PTM have been detected on proteins of saprophytic and pathogenic leptospires, and on specific proteins, including OmpL32 and LipL32 which are reported to be regulated, at least in part, by exposure to mammalian host conditions encountered during infection (Eshghi et al., 2012; Witchell et al., 2014). To test this hypothesis further, leptospires were collected directly from the urine of experimentally infected rats and compared to IV30 leptospires by 2-D immunoblotting with antiserum specific for the PTM trimethyllysine and acetyllysine (Figures 4, 5). The quantity of leptospires shed in the urine of experimentally infected rats is dependent on multiple factors including route of inoculation, dose, time post-infection, and strain (Athanazio et al., 2008; Bonilla-Santiago and Nally, 2011; unpublished observations). The use of an alternative strain for experimental infection of rats served to not only ensure that significant numbers of urinary derived leptospires could be collected for analysis by 2-D immunoblot, but also to ensure that our observations were relevant to more than one strain, and during actual infection as predicted by our model system for the cultivation of leptospires in vivo (Caimano et al., 2014). Collectively our results highlight that differences in protein modification with trimethyllysine and acetyllysine were observed between urinary vs. IV derived leptospires, indicating that these modifications were regulated, at least in part, by mammalian host signals. 2-D immunoblotting also suggested that LipL32 from IV30 leptospires contained trimethyllysine whilst urinary-derived leptospires did not; a finding which differs from the recent identification of trimethyllysine by mass spectrometry in urinary derived LipL32. The reasons for this are not yet clear and may be due to differences in modification potential of different strains of leptospires used in DMCs (Strain Fiocruz L1-130) compared to experimental infection (Strain RJ19115). In any case, a comprehensive analysis of protein structures of LipL32 as expressed during host infection is warranted. It has been hypothesized that protein PTM by leptospires may be dependent, at least partially, on elevated bacterial density (Witchell et al., 2014). Our analysis of DMC-cultivated leptospires is limited to those explanted at $\sim 10$ days; this time-point ensures recovery of sufficient motile leptospires (up to $3 \times 10^{8}$ per $\mathrm{ml}$ ) required for proteomics; this cell density in DMC corresponds to late logarithmic phase. Additional studies will be required to determine if cell density, similar to that encountered during persistent renal colonization, influences PTM. Similarly, given that DMC-cultivated leptospires are shielded from the host's immune system, it will be important to determine whether some PTMs occur in response to environmental (or physiological) stimuli vs. immune pressures encountered during persistent renal colonization.

In contrast to transcriptomic analyses which have the potential to determine the gene expression for all genes within a bacterium, gel based proteomics has inherent limitations. The genome of $L$. interrogans encodes more than 3,500 proteins (Nascimento et al., 2004), 69\% of which have a theoretical pI > 7.0 (Nally et al., 2007a). Our analyses were limited to those proteins with a $\mathrm{pI}$ of 3-7 since previous research has demonstrated that antigens reactive with convalescent sera are expressed within this range (Kositanont et al., 2007). Under these conditions, more than 1,700 protein spots were detected across all biological replicates of DMC- or IVcultivated leptospires. The sensitivity of gel-based proteomics is often limited to the most abundantly expressed proteins and this is reflected in those proteins we identified, given that whole leptospires were used. For example, the genes encoding DnaK, LipL32, GroEL, Elongation Factor Tu, and LipL41, are amongst the most transcribed genes in either DMC or IV leptospires (Caimano et al., 2014), and these were readily identified at the protein level. In contrast, those genes which are most differentially expressed between DMC and IV30 leptospires have (generally) an order of magnitude fewer transcripts (Caimano et al., 2014). In future work, we aim to increase sensitivity for the detection of outer membrane proteins, and their respective PTM, that interact with the host during infection; e.g., by enrichment of OM proteins with TX114 , and as required to detect the differential expression of the OM lipoprotein LipL36 in response to temperature (Nally et al., 2001b). Advantages of gel based proteomics include the 
ability to identify PTM associated with specific protein isoforms, and to perform immunoblots to determine which spots are reactive with serum from exposed animals (or other ligands of interest).

Post-translational methylation and acetylation have been implicated in protein activity, resistance to proteolysis, virulence (Calder et al., 2015), phase variation of pilin, type III secretion, chemotaxis, and motility (Kort et al., 1975; Barak and Eisenbach, 2001), stress responses (Ma and Wood, 2011), and metabolism (Ouidir et al., 2015). Bacterial pathogens express OM proteins which can contain multiple PTM, and interact directly with the host during infection. Whilst generally accepted that PTM modify protein function, studies investigating the consequences of regulating these in response to host infection are limited (Cain et al., 2014; Grangeasse et al., 2015). In pathogenic leptospires, PTM of outer membrane proteins are predicted to facilitate immune evasion, and thus persistence (Witchell et al., 2014). Our results advocate that differential protein PTM, including methylation and acetylation, are regulated in response to infection. Collectively, our results highlight the need to further examine regulatory processes employed by pathogenic leptospires to adapt to the host during infection. Our analyses confirm that leptospires cultivated within DMCs, in response to mammalian host conditions, are amenable to genomic, transcriptomic and proteomic analysis and that DMC leptospires can be used to define such regulatory pathways. Finally, our results highlight the need to consider how leptospires modify their proteins with PTM, as this can influence the success of candidate vaccine and diagnostic antigens.

\section{AUTHOR CONTRIBUTIONS}

Conceived and designed the experiments: JN, MC. Performed the experiments: JN, AG, SP, KS, JR, MC. Contributed resources/reagents/materials/analysis tools: JN, JR, JS, AM, MC. Wrote the paper: JN. Revised the paper: JN, AG, SP, KS, JR, JS, AM, MC.

\section{ACKNOWLEDGMENTS}

We thank Stephen Hyland, Ruben Bonilla-Santiago and Richard Hornsby for technical assistance running 2-D DIGE gels, immunoblots and experimental infections of rats respectively, and support from EU COST Action FA1002 on Farm Animal Proteomics. AG was supported by a Science without Borders fellowship from the Brazilian National Council for Scientific and Technological Development. This work was partially supported by NIH grants AI-29735 (MC) and research funds generously provided by Connecticut Children's Medical Center (MC). USDA is an equal opportunity provider and employer. Mention of trade names or commercial products in this publication is solely for the purpose of providing specific information and does not imply recommendation or endorsement by the U.S. Department of Agriculture.

\section{SUPPLEMENTARY MATERIAL}

The Supplementary Material for this article can be found online at: http://journal.frontiersin.org/article/10.3389/fcimb. 2017.00362/full\#supplementary-material

Supplementary Figure 1 | Two-dimensional gel electrophoresis of leptospires. As shown in Figure $\mathbf{1}$ but without labels.

Supplementary Table 1 | List of all differentially expressed proteins.

Supplementary Table 2 | Mass spectrometry data for all protein identifications Search parameters are provided in the parameters sheet. The summary sheet provides all significant hits which are highlighted in green, and proteins spots with more than one significant identification are highlighted in yellow. Proteins identifications that were returned as hypothetical or unknown were subject to BLAST (Altschul et al., 1990) and these identifications are italicized.

\section{REFERENCES}

Adler, B., Lo, M., Seemann, T., and Murray, G. L. (2011). Pathogenesis of leptospirosis: the influence of genomics. Vet. Microbiol. 153, 73-81. doi: 10.1016/j.vetmic.2011.02.055

Altschul, S. F., Gish, W., Miller, W., Myers, E. W., and Lipman, D. J. (1990). Basic local alignment search tool. J. Mol. Biol. 215, 403-410. doi: 10.1016/S0022-2836(05)80360-2

Athanazio, D. A., Silva, E. F., Santos, C. S., Rocha, G. M., Vannier-Santos, M. A., McBride, A. J., et al. (2008). Rattus norvegicus as a model for persistent renal colonization by pathogenic Leptospira interrogans. Acta Trop. 105, 176-180. doi: 10.1016/jactatropica.2007.10.012

Barak, R., and Eisenbach, M. (2001). Acetylation of the response regulator, CheY, is involved in bacterial chemotaxis. Mol. Microbiol. 40, 731-743. doi: 10.1046/j.1365-2958.2001.02425.x

Bolin, C. A., and Alt, D. P. (2001). Use of a monovalent leptospiral vaccine to prevent renal colonization and urinary shedding in cattle exposed to Leptospira borgpetersenii serovar hardjo. Am. J. Vet. Res. 62, 995-1000. doi: 10.2460/ajvr.2001.62.995

Bonilla-Santiago, R., and Nally, J. E. (2011). Rat model of chronic leptospirosis. Curr. Protoc. Microbiol. Chapter 12:Unit12E 3. doi: 10.1002/97804717 29259.mc12e03s 20
Breci, L. A., Tabb, D. L., Yates, J. R., and Wysocki, V. H. (2003). Cleavage Nterminal to proline: analysis of a database of peptide tandem mass spectra. Anal. Chem. 75, 1963-1971. doi: 10.1021/ac026359i

Bryk, R., Lima, C., Erdjument-Bromage, H., Tempst, P., and Nathan, C. (2002). Metabolic enzymes of mycobacteria linked to antioxidant defense by a thioredoxin-like protein. Science 295, 1073-1077. doi: 10.1126/science.1067798

Caimano, M. J., Sivasankaran, S. K., Allard, A., Hurley, D., Hokamp, K., Grassmann, A. A., et al. (2014). A model system for studying the transcriptomic and physiological changes associated with mammalian host-adaptation by Leptospira interrogans serovar copenhageni. PLoS Pathog. 10:e1004004. doi: 10.1371/journal.ppat.1004004

Cain, J. A., Solis, N., and Cordwell, S. J. (2014). Beyond gene expression: the impact of protein post-translational modifications in bacteria. J. Proteomics 97, 265-286. doi: 10.1016/j.jprot.2013.08.012

Calder, B., Soares, N. C., de Kock, E., and Blackburn, J. M. (2015). Mycobacterial proteomics: analysis of expressed proteomes and posttranslational modifications to identify candidate virulence factors. Expert Rev. Proteomics 12, 21-35. doi: 10.1586/14789450.2015.1007046

Cao, X.-J., Dai, J., Xu, H., Nie, S., Chang, X., Hu, B.-Y., et al. (2010). High-coverage proteome analysis reveals the first insight of protein modification systems in the pathogenic spirochete Leptospira interrogans. Cell Res. 20, 197-210. doi: $10.1038 /$ cr.2009.127 
Chu, Y., Zhu, Y., Chen, Y., Li, W., Zhang, Z., Liu, D., et al. (2016). aKMT catalyzes extensive protein lysine methylation in the hyperthermophilic archaeon Sulfolobus islandicus but is dispensable for the growth of the organism. Mol. Cell. Proteomics 15, 2908-2923. doi: 10.1074/mcp.M115. 057778

Costa, F., Hagan, J. E., Calcagno, J., Kane, M., Torgerson, P., Martinez-Silveira, M. S., et al. (2015). Global morbidity and mortality of leptospirosis: a systematic review. PLoS Negl. Trop. Dis. 9:e0003898. doi: 10.1371/journal.pntd.0003898

Coutinho, M. L., Matsunaga, J., Wang, L.-C., de la Peña Moctezuma, A., Lewis, M. S., Babbitt, J. T., et al. (2014). Kinetics of Leptospira interrogans infection in hamsters after intradermal and subcutaneous challenge. PLoS Negl. Trop. Dis. 8, e3307. doi: 10.1371/journal.pntd.0003307

Cullen, P. A., Cordwell, S. J., Bulach, D. M., Haake, D. A., and Adler, B. (2002). Global analysis of outer membrane proteins from Leptospira interrogans serovar Lai. Infect. Immun. 70, 2311-2318. doi: 10.1128/IAI.70.5.2311-2318.2002

Domingos, R. F., Vieira, M. L., Romero, E. C., Gonçales, A. P., de Morais, Z. M., Vasconcellos, S. A., et al. (2012). Features of two proteins of Leptospira interrogans with potential role in host-pathogen interactions. BMC Microbiol. 12:50. doi: 10.1186/1471-2180-12-50

Eshghi, A., Cullen, P. A., Cowen, L., Zuerner, R. L., and Cameron, C. E. (2009). Global proteome analysis of Leptospira interrogans. J. Proteome Res. 8, 4564-4578. doi: 10.1021/pr9004597

Eshghi, A., Pappalardo, E., Hester, S., Thomas, B., Pretre, G., and Picardeau, M. (2015). Pathogenic Leptospira interrogans exoproteins are primarily involved in heterotrophic processes. Infect. Immun. 83, 3061-3073. doi: 10.1128/IAI.00427-15

Eshghi, A., Pinne, M., Haake, D. A., Zuerner, R. L., Frank, A., and Cameron, C. E. (2012). Methylation and in vivo expression of the surface-exposed Leptospira interrogans outer-membrane protein OmpL32. Microbiology 158(Pt 3), 622-635. doi: 10.1099/mic.0.054767-0.

Finn, R. D., Attwood, T. K., Babbitt, P. C., Bateman, A., Bork, P., Bridge, A. J., et al. (2017). InterPro in 2017-beyond protein family and domain annotations. Nucleic Acids Res. 45, D190-D199. doi: 10.1093/nar/gkw1107

Fouts, D. E., Matthias, M. A., Adhikarla, H., Adler, B., Amorim-Santos, L., Berg, D. E., et al. (2016). What makes a bacterial species pathogenic?: comparative genomic analysis of the genus Leptospira. PLoS Negl. Trop. Dis. 10:e0004403. doi: 10.1371/journal.pntd.0004403

Grangeasse, C., Stülke, J., and Mijakovic, I. (2015). Regulatory potential of post-translational modifications in bacteria. Front. Microbiol. 6:500. doi: $10.3389 /$ fmicb. 2015.00500

Grassmann, A. A., McBride, A. J. A., Nally, J. E., and Caimano, M. J. (2015). Generation of mammalian host-adapted Leptospira interrogans by cultivation in peritoneal dialysis membrane chamber implantation in rats. Bio protoc. 5:e1536. doi: 10.21769/BioProtoc.1536

Haake, D. A., Chao, G., Zuerner, R. L., Barnett, J. K., Barnett, D., Mazel, M., et al. (2000). The leptospiral major outer membrane protein LipL32 is a lipoprotein expressed during mammalian infection. Infect. Immun. 68, 2276-2285. doi: 10.1128/IAI.68.4.2276-2285.2000

Hong, Y., Cao, X., Han, Q., Yuan, C., Zhang, M., Han, Y., et al. (2016). Proteomewide analysis of lysine acetylation in adult Schistosoma japonicum worm. J. Proteomics 148, 202-212. doi: 10.1016/j.jprot.2016.08.008

Jones, P., Binns, D., Chang, H.-Y., Fraser, M., Li, W., McAnulla, C., et al. (2014). InterProScan 5: genome-scale protein function classification. Bioinformatics 30, 1236-1240. doi: 10.1093/bioinformatics/btu031

Kort, E. N., Goy, M. F., Larsen, S. H., and Adler, J. (1975). Methylation of a membrane protein involved in bacterial chemotaxis. Proc. Nat. Acad. Sci. U.S.A. 72, 3939-3943. doi: 10.1073/pnas.72.10.3939

Kositanont, U., Saetun, P., Krittanai, C., Doungchawee, G., Tribuddharat, C., and Thongboonkerd, V. (2007). Application of immunoproteomics to leptospirosis: towards clinical diagnostics and vaccine discovery. Proteomics Clin. Appl. 1, 400-409. doi: 10.1002/prca.200600805

Lo, M., Bulach, D. M., Powell, D. R., Haake, D. A., Matsunaga, J., Paustian, M. L., et al. (2006). Effects of temperature on gene expression patterns in Leptospira interrogans serovar Lai as assessed by whole-genome microarrays. Infect. Immun. 74, 5848-5859. doi: 10.1128/IAI.00755-06

Lo, M., Cordwell, S. J., Bulach, D. M., and Adler, B. (2009). Comparative transcriptional and translational analysis of leptospiral outer membrane protein expression in response to temperature. PLoS Negl. Trop. Dis. 3:e560. doi: 10.1371/journal.pntd.0000560

Lo, M., Murray, G. L., Khoo, C. A., Haake, D. A., Zuerner, R. L., and Adler, B. (2010). Transcriptional response of Leptospira interrogans to iron limitation and characterization of a PerR homolog. Infect. Immun. 78, 4850-4859. doi: 10.1128/IAI.00435-10

Ma, Q., and Wood, T. K. (2011). Protein acetylation in prokaryotes increases stress resistance. Biochem. Biophys. Res. Commun. 410, 846-851. doi: 10.1016/j.bbrc.2011.06.076

Matsunaga, J., Lo, M., Bulach, D. M., Zuerner, R. L., Adler, B., and Haake, D. A. (2007). Response of Leptospira interrogans to physiologic osmolarity: relevance in signaling the environment-to-host transition. Infect. Immun. 75, 2864-2874. doi: 10.1128/IAI.01619-06

Matsunaga, J., Schlax, P. J., and Haake, D. A. (2013). Role for cisacting RNA sequences in the temperature-dependent expression of the multiadhesive lig proteins in Leptospira interrogans. J. Bacteriol. 195, 5092-5101. doi: 10.1128/JB.00663-13

Matsunaga, J., Werneid, K., Zuerner, R. L., Frank, A., and Haake, D. A. (2006). LipL46 is a novel surface-exposed lipoprotein expressed during leptospiral dissemination in the mammalian host. Microbiology 152, 3777-3786. doi: 10.1099/mic.0.29162-0

Matsunaga, J., Young, T. A., Barnett, J. K., Barnett, D., Bolin, C. A., and Haake, D. A. (2002). Novel 45-kilodalton leptospiral protein that is processed to a 31-kilodalton growth-phase-regulated peripheral membrane protein. Infect. Immun. 70, 323-334. doi: 10.1128/IAI.70.1.323-334.2002

McBride, A. J., Athanazio, D. A., Reis, M. G., and Ko, A. I. (2005). Leptospirosis. Curr. Opin. Infect. Dis. 18, 376-386. doi: 10.1097/01.qco.0000178824.05 $715.2 \mathrm{c}$

Monahan, A. M., Callanan, J. J., and Nally, J. E. (2008). Proteomic analysis of Leptospira interrogans shed in urine of chronically infected hosts. Infect. Immun. 76, 4952-4958. doi: 10.1128/IAI.00511-08

Murray, G. L., Morel, V., Cerqueira, G. M., Croda, J., Srikram, A., Henry, R., et al. (2009). Genome-wide transposon mutagenesis in pathogenic Leptospira species. Infect. Immun. 77, 810-816. doi: 10.1128/IAI.01293-08

Nally, J. E., Artiushin, S., and Timoney, J. F. (2001a). Molecular characterization of thermoinduced immunogenic proteins Qlp42 and Hsp15 of Leptospira interrogans. Infect. Immun. 69, 7616-7624. doi: 10.1128/IAI.69.12.7616-7624.2001

Nally, J. E., Monahan, A. M., Miller, I. S., Bonilla-Santiago, R., Souda, P., and Whitelegge, J. P. (2011). Comparative proteomic analysis of differentially expressed proteins in the urine of reservoir hosts of leptospirosis. PLoS ONE 6:e26046. doi: 10.1371/journal.pone.0026046

Nally, J. E., Timoney, J. F., and Stevenson, B. (2001b). Temperature-regulated protein synthesis by Leptospira interrogans. Infect. Immun. 69, 400-404. doi: 10.1128/IAI.69.1.400-404.2001

Nally, J. E., Whitelegge, J. P., Aguilera, R., Pereira, M. M., Blanco, D. R., and Lovett, M. A. (2005). Purification and proteomic analysis of outer membrane vesicles from a clinical isolate of Leptospira interrogans serovar Copenhageni. Proteomics 5, 144-152. doi: 10.1002/pmic.200400880

Nally, J. E., Whitelegge, J. P., and Carroll, J. A. (2007b). Proteomic strategies to elucidate pathogenic mechanisms of spirochetes. Proteomics Clin. Appl. 1, 1185-1197. doi: 10.1002/prca.200700090

Nally, J. E., Whitelegge, J. P., Bassilian, S., Blanco, D. R., and Lovett, M. A. (2007a). Characterization of the outer membrane proteome of Leptospira interrogans expressed during acute lethal infection. Infect. Immun. 75, 766-773. doi: 10.1128/IAI.00741-06

Nascimento, A. L., Ko, A. I., Martins, E. A., Monteiro-Vitorello, C. B., Ho, P. L., Haake, D. A., et al. (2004). Comparative genomics of two Leptospira interrogans serovars reveals novel insights into physiology and pathogenesis. J. Bacteriol. 186, 2164-2172. doi: 10.1128/JB.186.7.2164-2172.2004

Ouidir, T., Cosette, P., Jouenne, T., and Hardouin, J. (2015). Proteomic profiling of lysine acetylation in Pseudomonas aeruginosa reveals the diversity of acetylated proteins. Proteomics 15, 2152-2157. doi: 10.1002/pmic.201500056

Paizs, B., and Suhai, S. (2005). Fragmentation pathways of protonated peptides. Mass Spectrom. Rev. 24, 508-548. doi: 10.1002/mas.20024

Patarakul, K., Lo, M., and Adler, B. (2010). Global transcriptomic response of Leptospira interrogans serovar Copenhageni upon exposure to serum. BMC Microbiol. 10:31. doi: 10.1186/1471-2180-10-31 
Picardeau, M. (2015). Genomics, proteomics, and genetics of leptospira. Curr. Top. Microbiol. Immunol. 387, 43-63. doi: 10.1007/978-3-662-45059-8_4

Pinne, M., Choy, H. A., and Haake, D. A. (2010). The OmpL37 surfaceexposed protein is expressed by pathogenic Leptospira during infection and binds skin and vascular elastin. PLoS Negl. Trop. Dis. 4:e815. doi: 10.1371/journal.pntd.0000815

Printz, B., Sergeant, K., Lutts, S., Guignard, C. D., Renaut, J., and Hausman, J.-F. (2013). From tolerance to acute metabolic deregulation: contribution of proteomics to dig into the molecular response of alder species under a polymetallic exposure. J. Proteome Res. 12, 5160-5179. doi: 10.1021/pr40 0590d

Qin, J.-H., Sheng, Y.-Y., Zhang, Z.-M., Shi, Y.-Z., He, P., Hu, B.-Y., et al. (2006). Genome-wide transcriptional analysis of temperature shift in L. interrogans serovar lai strain 56601. BMC Microbiol. 6:51. doi: 10.1186/1471-2180-6-51

Ricaldi, J. N., Fouts, D. E., Selengut, J. D., Harkins, D. M., Patra, K. P., Moreno, A., et al. (2012a). Whole genome analysis of Leptospira licerasiae provides insight into leptospiral evolution and pathogenicity. PLoS Negl. Trop. Dis. 6:e1853. doi: 10.1371/journal.pntd.0001853

Ricaldi, J., Matthias, M. A., Vinetz, J. M., and Lewis, A. L. (2012b). Expression of sialic acids and other nonulosonic acids in Leptospira. BMC Microbiol. 12:161. doi: 10.1186/1471-2180-12-161

Ristow, P., Bourhy, P., da Cruz McBride, F. W., Figueira, C. P., Huerre, M., Ave, P., et al. (2007). The OmpA-like protein Loa22 is essential for leptospiral virulence. PLoS Pathog. 3:e97. doi: 10.1371/journal.ppat.0030097

Rojas, P., Monahan, A. M., Schuller, S., Miller, I. S., Markey, B. K., and Nally, J. E. (2010). Detection and quantification of leptospires in urine of dogs: a maintenance host for the zoonotic disease leptospirosis. Eur. J. Clin. Microbiol. Infect. Dis. 29, 1305-1309. doi: 10.1007/s10096-010-0991-2

Schmidt, A., Beck, M., Malmström, J., Lam, H., Claassen, M., Campbell, D., et al. (2011). Absolute quantification of microbial proteomes at different states by directed mass spectrometry. Mol. Syst. Biol. 7, 510. doi: 10.1038/msb.2011.37

Schuller, S., Sergeant, K., Renaut, J., Callanan, J. J., Scaife, C., and Nally, J. E. (2015). Comparative proteomic analysis of lung tissue from guinea pigs with Leptospiral Pulmonary Haemorrhage Syndrome (LPHS) reveals a decrease in abundance of host proteins involved in cytoskeletal and cellular organization. J. Proteomics 122, 55-72. doi: 10.1016/j.jprot.2015.03.021

Shang, E. S., Summers, T. A., and Haake, D. A. (1996). Molecular cloning and sequence analysis of the gene encoding LipL41, a surface-exposed lipoprotein of pathogenic Leptospira species. Infect. Immun. 64, 2322-2330.

Stewart, P. E., Carroll, J. A., Olano, L. R., Sturdevant, D. E., and Rosa, P. A. (2016). Multiple posttranslational modifications of Leptospira biflexa proteins as revealed by proteomic analysis. Appl. Environ. Microbiol. 82, 1183-1195. doi: 10.1128/AEM.03056-15

Vizcaíno, J. A., Deutsch, E. W., Wang, R., Csordas, A., Reisinger, F., Rios, D., et al. (2014). ProteomeXchange provides globally coordinated proteomics data submission and dissemination. Nat. Biotechnol. 32, 223-226. doi: 10.1038/nbt.2839

Witchell, T. D., Eshghi, A., Nally, J. E., Hof, R., Boulanger, M. J., Wunder, E. A., Jr. et al. (2014). Post-translational modification of LipL32 during Leptospira interrogans infection. PLoS Negl. Trop. Dis. 8:e3280. doi: 10.1371/journal.pntd.0003280

Wolff, D. G., Castiblanco-Valencia, M. M., Abe, C. M., Monaris, D., Morais, Z. M., Souza, G. O., et al. (2013). Interaction of Leptospira elongation factor $\mathrm{Tu}$ with plasminogen and complement factor $\mathrm{H}$ : a metabolic leptospiral protein with moonlighting activities. PLoS ONE 8:e81818. doi: 10.1371/journal.pone.0081818

Xue, F., Dong, H., Wu, J., Wu, Z., Hu, W., Sun, A., et al. (2010). Transcriptional responses of Leptospira interrogans to host innate immunity: significant changes in metabolism, oxygen tolerance, and outer membrane. PLoS Negl. Trop. Dis. 4:e857. doi: 10.1371/journal.pntd.0000857

Zeng, L., Zhang, Y., Zhu, Y., Yin, H., Zhuang, X., Zhu, W., et al. (2013). Extracellular proteome analysis of Leptospira interrogans serovar Lai. OMICS 17, 527-535. doi: 10.1089/omi.2013.0043

Zhukova, A., Fernandes, L. G., Hugon, P., Pappas, C. J., Sismeiro, O., Coppée, J.-Y., et al. (2017). Genome-wide transcriptional start site mapping and sRNA identification in the pathogen Leptospira interrogans. Front. Cell. Infect. Microbiol. 7:10. doi: 10.3389/fcimb.2017.00010

Zuerner, R. L. (2005). Laboratory maintenance of pathogenic Leptospira. Curr. Protoc. Microbiol. Chapter 12:Unit 12E.1. doi: 10.1002/97804 71729259.mc12e01s00

Conflict of Interest Statement: The authors declare that the research was conducted in the absence of any commercial or financial relationships that could be construed as a potential conflict of interest.

Copyright $\odot 2017$ Nally, Grassmann, Planchon, Sergeant, Renaut, Seshu, McBride and Caimano. This is an open-access article distributed under the terms of the Creative Commons Attribution License (CC BY). The use, distribution or reproduction in other forums is permitted, provided the original author(s) or licensor are credited and that the original publication in this journal is cited, in accordance with accepted academic practice. No use, distribution or reproduction is permitted which does not comply with these terms. 